\title{
A new method of electrodes placement to improve QRS detection in real-time stress ECG acquisition
}

- Le Cao Dang

- Nguyen Hoang Tan

- Phan Hoai Nam

- Thai Minh Quoc

Ho Chi Minh city University of Technology, VNU-HCM

(Manuscript Received on August 01 ${ }^{\text {st }}$, 2015, Manuscript Revised August 27 ${ }^{\text {th }}$, 2015)

ABSTRACT:

In dynamic threshold method to detect QRS complex from ECG signal, especially in real-time application, there are two main issues: baseline drift and noise. This paper introduces an improved QRS complex detecting method using dynamic threshold algorithm combined with a new method of electrodes placement to minimize baseline drift and different types of noise in real-time ECG acquisition with moving patients. Our method proved to be more effective in detecting QRS complex with less error due to minimized baseline drift and noise in original ECG signal. .

Key words: WB lead, QRS complex detection algorithm, dynamic threshold, ECG.

\section{INTRODUCTION}

As a vital sign, heart rate is one of the most important biological parameters of living human body. In ECG data, QRS complex has a particular waveform with high R-peak amplitude in compared with baseline signal. Due to its special property, QRS complex is often used as triggering signal to register heart beats and calculate heart rate. In practice, real-time ECG processing is an sophisticated procedure because ECG signal amplitude changes continuously and unstably due to body movements such as breathing, muscle contraction etc. Pan and Tompkins [1] developed an algorithm that automatically changes threshold and parameter in each heart cycle to adapt continuous real-time changing of ECG. signal. The accuracy of dynamic threshold algorithm relies mainly on how it changes its threshold. Xue et al. [2] developed an adaptive filter algorithm based on artificial neural network to detect QRS complex. Dotsinsky and Stoyanov [3] introduced heuristic algorithm for ventricular beats detection in single lead ECG processing, based on steep edges and sharp peaks evaluation of ECG signal components. Although mentioned researches gave relatively good results, complex and sophisticated algorithms have prevented their application in practical real-time measurements. In 2008, Chouhan et al. [4] introduced a new algorithm based on first derivative and adaptive quantized threshold. The main advantage of first derivative over other methods is its easier implementation in practice. In 2009, Elgendi et al. [5] published an algorithm which improves the effectiveness of dynamic threshold in QRS complex detection. The result was evaluated on 19 data of MIT/BIH Arrhythmia Database with $97.5 \%$ sensitivity and positive predictivity reached $99.9 \%$. 
However many ECG applications do not require highly accurate ECG signal acquisition, e.g. in HRV analysis, only the accuracy of QRS complex detection is concerned to calculate heart rate. Especially in wearable device on moving patients, minimal number of electrodes and adequate electrodes placement position to ensure comfort and reduce activity noise are the keys of accurate detection. In addition, placing electrodes on young female patients' chest by conventional leads causes bad feeling and may hinder measurement procedure. This paper represents a new method of electrodes placement around the waist called waist-back (WB) lead with the intention to minimize baseline drift and activity noise of ECG signal for QRS complex detection in real-time measurement for moving patients.

\section{METHODS}

\subsection{Subject}

Thirteen healthy volunteers, with no recorded cardiac disease, 4 males and 9 females, aged 22 24 years old were recruited for ECG data acquisition in this study.

\subsection{Data acquisition}

ECG data were recorded using BIOPAC MP36 data acquisition unit with Biopac Student Lab software, BIOPAC SS2L Electrodes lead set and disposable electrodes. The signal was filtered using MP36 hardware/software band-pass filter $0.5 \mathrm{~Hz}$ to $35 \mathrm{~Hz}$, sampling frequency $1000 \mathrm{~Hz}$. ECG signals from each subject were recorded in 5 different types of activities: deep breath during sitting down (RB), upper limb movement (AM), lower limb movement (LM), full body movement (BM), deep breath during standing (SB). Each activity lasts 2 minutes and intermittent resting time of at least 3 minutes.

$\mathrm{RB}$ - subjects are asked to sit on an elbow chair, relaxing their back, closing their eyes and deeply breathing.

SB - subjects are asked to stand, minimizing body movement, opening both eyes, focusing on one spot and breathing deeply.

LM - subjects are asked to stand, minimizing upper body movement, performing marching movement.
AM - subjects are asked to stand, minimizing lower body movement, performing vertical lift arm movement.

BM - subjects are asked to stand, performing marching movement with simultaneous arms and legs movement.

Electrodes placement positions are described as follows: $4-5 \mathrm{~cm}$ upward (vertical) from belly button is point A (Figure 1). From A, take a perimeter $(\mathrm{P})$ of the waist, parallel to transverse plan. This perimeter cuts the spinal cord at point B. Take $\mathrm{C}$ and $\mathrm{D}$ on $(\mathrm{P})$ which $\mathrm{B}$ is the symmetric point of $\mathrm{CD}$ segment. $\mathrm{CD}$ length is equal to $30 \%$ measure of waist perimeter. $\mathrm{C}$ is connected to $(+), \mathrm{D}$ is connected to (-) and B is connected to (Ref) terminal of SS2L electrodes lead set.

In principle, the potential vector of two point $\mathrm{C}$ and D is parallel to LEAD I in 3 ECG leads based on Einthoven triangle. To study the characteristics of WB lead, additional recording from LEAD I and LEAD III is also acquired simultaneously.

\subsection{Data analysis}

Data were processed by MATLAB to extract baseline. From baseline data of each subject in different exercises standard deviation values (SDB) were calculated and statistical tests were performed to evaluate the relationship.

The baseline extraction was performed using Discrete Wavelet Transform (DWT) algorithm. The frequency of the baseline wander is usually in a range below $0.1 \mathrm{~Hz}$ in rest ECG and $0.65 \mathrm{~Hz}$ during stress test [6]. Calculated data have showed good results of using the mother wave Daubechies11 (db11) with level $\mathrm{n}=9$ to extract baseline in DWT algorithm. Statistical results have showed mean of CE reached $99.9924 \%$ and mean of CB was $99.9150 \%$, where CE is the percentage result correlation between the original noise-free ECG and the ECG reconstruction and $\mathrm{CB}$ is the correlation between original baseline variation signal and the baseline reconstruction [6]. 

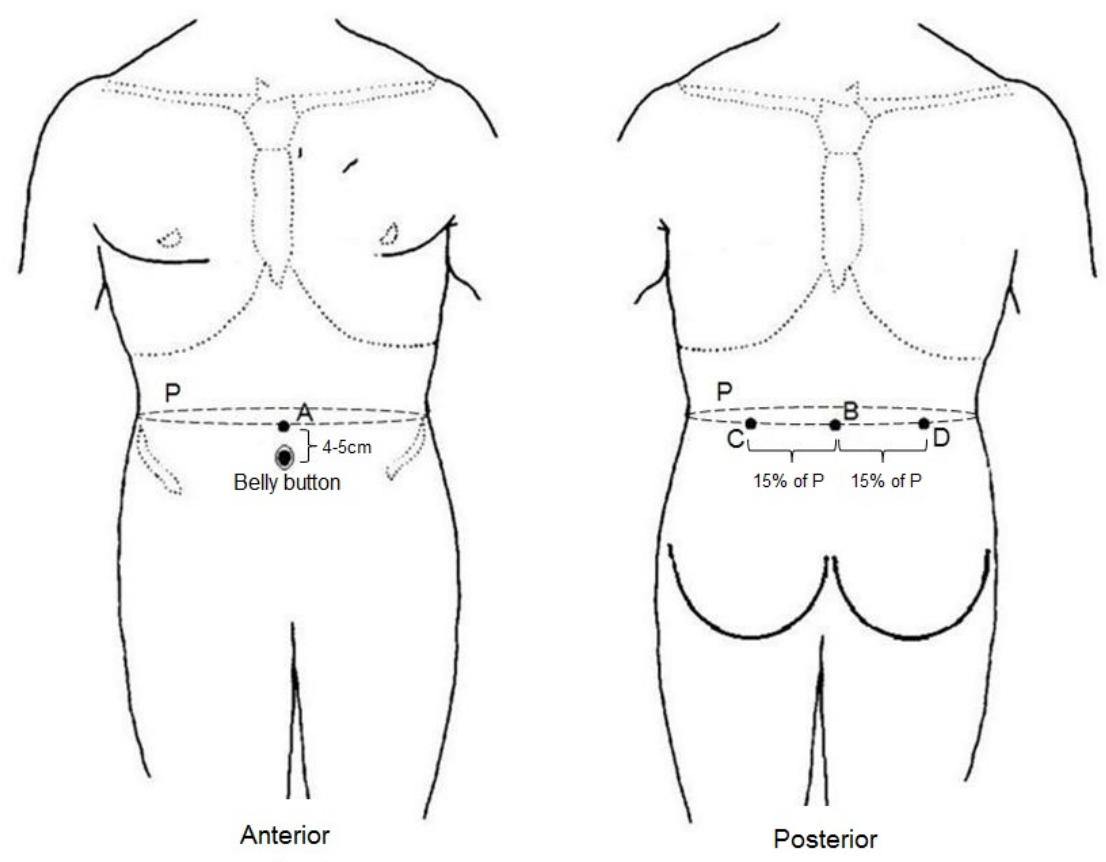

Figure 1. Electrodes placement positions for WB lead

\section{RESULTS}

195 baseline data were tested by two normally distributed algorithms AndersonDerling and Kolmoforow-Smirnov. The results showed 195/195 baseline data files following normal distribution. ANOVAs test also show the statistical significance difference among all baselines amplitude across all leads in different exercises.

The baseline extracted from ECG of each subject were observed visually, based on that the number of subjects having the least baseline fluctuations in different exercises were counted, results are illustrated in Figure 3. Obviously, lead

III has the largest baseline fluctuations. With increasing the level of body movement in exercise (RB - SB - LM - AM - BM), the number of subjects having the least baseline fluctuations tends to increase at lead WB and to decrease at lead I. In the exercise group having body movement (LM, AM and $\mathrm{BM}$ ), the number of subjects having the least baseline fluctuations at lead WB is equal or bigger than one at lead I.

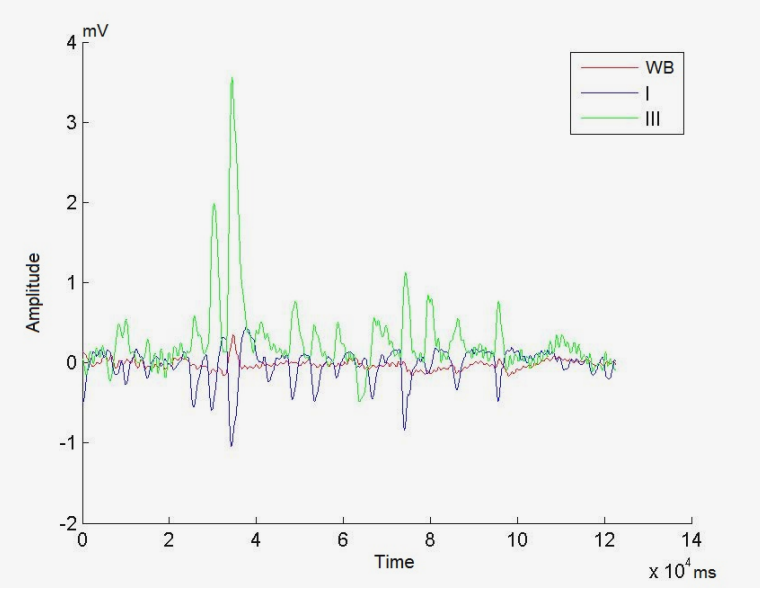

Figure 2. Baseline amplitude at 3 leads WB, I and III were extracted from ECG data.

Similarly SDB values for all cases were calculated. The results of number of subjects having the least SDB in different exercises are illustrated in Figure 4. The number of subjects having the least SDB at lead WB tends to 
increase significantly when the exercises change from $\mathrm{RB}$ to $\mathrm{SB}, \mathrm{LM}$ and $\mathrm{AM}$. Inversely, mentioned number dropped at lead I. In exercise $\mathrm{BM}$, the number of subjects having the least SDB at lead WB and lead I are approximately equal.

\section{DISCUSSION}

The difference of baselines of mentioned leads is statistically significant. Relatively, SDB is a good index to measure the baseline fluctuation. Visual evaluation of baseline fluctuation (Figure 3) have showed significant similarity with calculated evaluation (Table 1) based on the number of subjects having minimum SDB (Figure 4).

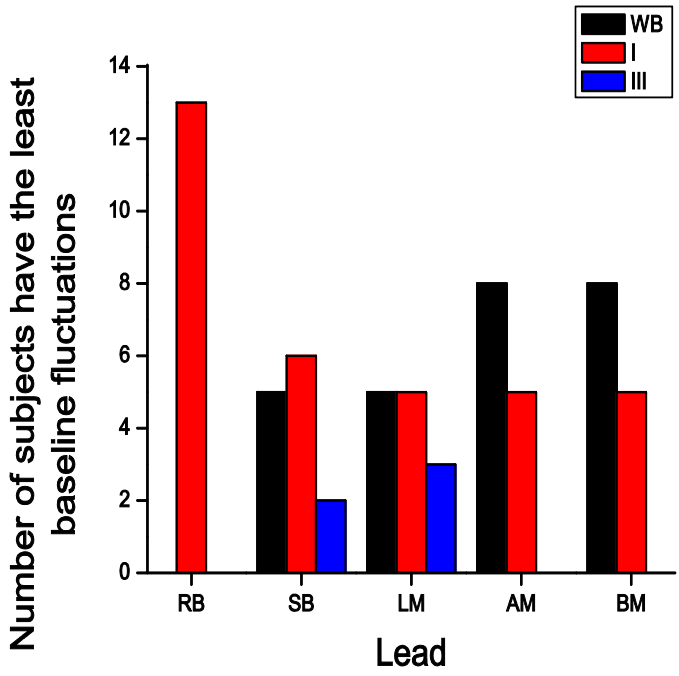

Figure 3. Visual evaluation of the number of subjects having the least baseline fluctuations at 3 lead

(WB, I and III) in different exercises.

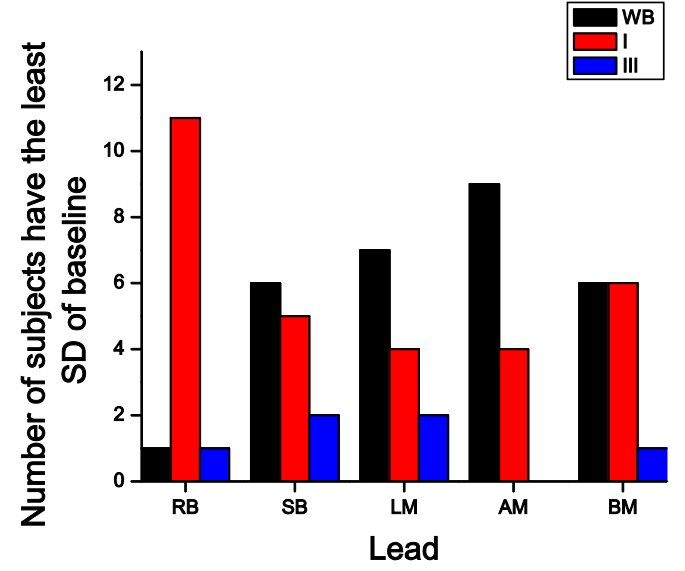

Figure 4. The number of subjects having the least SDB at 3 leads (WB, I and III) in different exercises.

Especially, in the exercise group having body movement, lead WB tends to have the least fluctuation and the biggest number of subjects having minimum SDBs.

The statistical results indicated the significant difference between lead WB and lead III. Lead III usually provides the highest disparity of R-peak from baseline in ECG recording on limb leads. This is a considerable advantage in applications for recognizing and detection QRS complexes. However, placing electrode in lead III will cause obstacle in movement, not to mention the decline in signal quality when recording realtime stress or movement ECG. These problems will have to be encountered in the lead I too. Lead WB is a solution to minimize the movement obstructing and to ensure better stability of the baseline.

Table 1 Parameters of SD (milivolt) of baselines

\begin{tabular}{|c|c|c|c|c|c|c|}
\hline \multirow{2}{*}{ Exercise } & \multicolumn{3}{|c|}{ Mean** } & \multicolumn{3}{|l|}{$S D^{\star \star}$} \\
\hline & WB & I & III & WB & I & III \\
\hline RB & .2311 & .1159 & .2520 & .2214 & .0648 & .1577 \\
\hline SB & .2406 & .2029 & .3805 & .1670 & .0991 & .2471 \\
\hline LM & .2819 & .2524 & .3808 & .1907 & .1518 & .2536 \\
\hline AM & .1944 & .2401 & .4521 & .0970 & .0933 & .2112 \\
\hline BM & .2244 & .2938 & .4870 & .1196 & .1693 & .3013 \\
\hline
\end{tabular}




\section{CONCLUSION}

The results have proven that the acquisition of ECG signal via WB lead is a good solution providing better quality of signal in recording real-time stress or movement ECG.
The reliability of the results in this research depends largely on the subjects. To increase the reliability of the results and further characteristics of lead WB, this research needs to be improved with larger number of subjects.

\section{Phương pháp đặt điện cực mới cải thiện ghi nhận phức bộ QRS trong đo điện tim gắng sức theo thời gian thực}

- Lê Cao Đăng

- Nguyễn Hoàng Tân

- Phan Hoài Nam

- Thái Minh Quốc

Trường Đại học Bách Khoa, ĐHQG-HCM

\section{TÓM TÁT}

Trong các phương pháp ghi nhận phức bộ QRS bằng ngưỡng động, sự trôi tín hiệu nền và ảnh hưởng nhiễu là hai vấn đề quan trọng cần quan tâm. Bài báo này trình bày một phương pháp mới kết hợp giữa việc thay đổi vị trí đặt điện cực theo các đạo trình truyền thống và

phương pháp dò đỉnh $R$ bằng ngướng động để giảm thiểu vấn đề trôi đường nền và nhiễu khi thu nhận và phân tích xác định phức bộ QRS từ tín hiệu ECG theo thời gian thực của đối tượng đang vận động.

Từ khóa: kênh WB, phức bộ QRS, ngưỡng động, điện tim, ECG.

\section{REFERENCES}

[1]. J. Pan and W. J. Tompkins, A real-time QRS detection algorithm. IEEE Trans. Biomed. Eng. 32(3) (1985) 230-236.

[2]. Q. Xue, Y. H. Hu, and W. J. Tompkins, Neural-network-based adaptive matched filtering for QRS detection. IEEE Trans Biomed Eng. 39(4) (1992), 317-29.

[3]. I. Dotsinsky, T. Stoyanov, Ventricular beat detection in single channel electrocardiograms. Biomed. Eng. Online. 3:3, (2004).

[4]. V. S. Chouhan and S. S. Mehta, Detection of QRS complexes in 12-lead ECG using adaptive quantized threshold. International Journal of Computer Science and Network Security, Vol. 8, No. 1 (2008) 155-163.

[5]. M. Elgendi, M. Jonkman, F. D. Boer, Improved QRS detection algorithm using dynamic thresholds. International Journal of Hybrid Information Technology 2 (2009) 65-80.

[6]. A. Khawaja, Automatic ECG Analysis using Principal Component Analysis and Wavelet Transformation, KIT Scientific Publishing (2009). 